\title{
Polyandry and allele frequency differences between the sexes in the ant Formica aquilonia
}

\author{
PEKKA PAMILO \\ Department of Genetics, Uppsala University, Box 7003, 75007 Uppsala, Sweden
}

\begin{abstract}
Genetic mother-offspring analyses based on six enzyme gene loci show that about 60 per cent of the females of the mound-building red wood ant Formica aquilonia mate with several males. The number of matings inferred from the offspring genotypes range from one to six, the arithmetic mean being 1.94. The mates do not contribute equally in the inseminations; in the case of two matings, one male is estimated to inseminate on average 77 per cent of the offspring. The average relatedness among the offspring of a single female is 0.6 , corresponding to the effective number of matings of 1.43. Three of the six loci show remarkable allele frequency differences between the sexes. At each of these loci the males virtually lack the alleles present in females with frequencies 0.18 at $\mathrm{Me}$, 0.25 at $P g k$ and 0.27 at $\mathrm{Gpi}$. Segregation analyses indicate normal Mendelian inheritance at these loci and the difference between the sexes seem likely to result from selection.
\end{abstract}

Keywords: colony-level selection, Formica aquilonia polyandry, relatedness, sex-specific allele frequencies, social insects.

\section{Introduction}

It is commonly thought that multiple mating can be disadvantageous to females owing to increased risks (e.g. Moritz, 1985), although such effects have rarely been documented (Gwynne, 1989). The major result of polyandry is a genetically diverse progeny. In sexually reproducing organisms, genetic diversity among the offspring may help some of them to survive in a patchy environment (Williams, 1975). In eusocial insects the same applies to the sexual offspring that disperse whereas the sterile workers stay together in the parental nest and the genetically diverse colony faces the environment as a collective unit. The hypotheses explaining polyandry in eusocial insects must therefore take into account its possible consequences for the whole colony. The hypotheses can be classified depending on whether polyandry is considered adaptive to the individual females (queens), to the whole colony, to the population, or whether the hypothesis refers to the queen-worker conflict over colony reproduction (Crozier \& Page, 1985; Pamilo, 1991a). Two hypotheses, both based on colony-level phenomena, have been particularly favoured in recent literature: they are referred to here as a load hypothesis and a diversity hypothesis.

The load hypothesis is based on the distribution of diploid males among nests (Page, 1980; Crozier \&
Page, 1985). Individuals homozygous for the sexdetermining locus (or loci) develop into diploid males in the honeybee (Mackensen, 1951), in the fire ant (Ross \& Fletcher, 1985a) and probably in many other, normally male haploid, hymenopteran species (Crozier, 1975). Such diploid males are non-viable or sterile and cause a burden to the colony. As frequencydependent selection should lead to a large number of equally freqent sex alleles, the frquency of diploid males in the population remains low. Multiple mating by the females affects the distribution of diploid males among the colonies, but the total frequency of diploid males in the population remains unaffected. Polyandry increases the proportion of colonies suffering from the load and at the same time decrease the average load in those colonies that are affected. The fitness effects depend on how the colony success changes as the function of the proportion of diploid offspring developing into males (Crozier \& Page, 1985).

The diversity hypothesis emphasizes the adaptive significance of the genetic variation among the worker force (Crozier \& Page, 1985). A special aspect of that hypothesis was proposed by Hamilton (1987) and Sherman et al. (1988) who suggested that genetic diversity of the worker force can improve the resistance of the whole colony to diseases. Some support for this idea comes from the kin-biased transmission of 
trypanosome parasites in bumblebees (Shykoff \& Schmid-Hempel, 1991a,b).

The diversity hypothesis predicts that multiple mating is particularly adaptive in species with monogynous colonies (i.e. colonies with a single queen). Increasing the number of coexisting reproductive queens in a colony (polygyny of colonies) raises the genetic diversity among nest members to an extent that quickly dilutes the effects of polyandry. The predictions of the load hypothesis depend on how sensitive the colonies are to the existence of diploid males. The observational evidence suggests that queens founding new nests independently should be monandrous because multiple mating decreases the success of colony foundation by increasing the chance of having diploid males among the offspring (Ross \& Fletcher, 1986). The level of polyandry in species with polygynous colonies is expected to depend on selection at the individual level as polyandry does not add much to the genetic diversity of such colonies.

In this paper, I present results from genetic mother-offspring analyses in an ant Formica aquilonia which typically was highly polygynous colonies with tens or hundreds of reproductive queens in the same nest (Pamilo, 1982; Rosengren \& Pamilo, 1983). The aims of the analyses are to estimate the level of polyandry in order to evaluate the above mentioned hypotheses, to estimate the proportion of offspring inseminated by each of the mates, to estimate the mating types, and to confirm the Mendelian inheritance of the observed allozyme variation.

\section{Materials and methods}

\section{Laboratory methods}

The study is based mainly on laboratory cultures of Formica aquilonia. The ants for these cultures were collected from two nests at the Tvärminne Zoological Station, Hanko in southwestern Finland. There were
200 old queens ( 100 from each nest) and a few thousand workers from the respective nests were collected in early May 1987 and brought to the laboratory. The laboratory nests were constructed from two ceramic flower pots, one within the other, and the ants placed their nest chambers in the space between the bottoms (Pamilo, 1982). One queen and about 100 workers were placed in each such nest and the offspring were removed from the successful nests in July as pupae. The genotypes of the offspring and the mother queen were analysed at six loci. In all, 113 laboratory nests produced offspring, all of which were workers. The mean number of offspring used in the electrophoretic study was 22.4 per nest (s.d. $=15.5$ ) (Table 1 ).

The nests used as the source of the old queens belong to a group of nests within a two hectare area. To characterize the population structure, 10-30 workers from each of 14 nests and 131 males from three nests (collected in 1990) in the same population of $F$. aquilonia were also studied electrophoretically.

The genotypes were determined using enzyme electrophoresis. The pupae were individually homogenized in $30 \mu \mathrm{l}$ of distilled water for the analysis. The gaster of adult workers was removed and the head and thorax were first rinsed in water before homogenizing them in $30 \mu \mathrm{l}$ of water ( $60 \mu \mathrm{l}$ for sexuals). The enzyme phenotypes were resolved by horizontal starch gel electrophoresis. The buffers used were (i) tray: $135 \mathrm{~mm}$

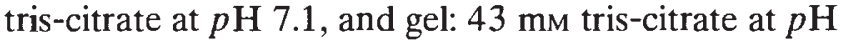
8.4 (Varvio-Aho \& Pamilo, 1980); (ii) tray: $135 \mathrm{~mm}$

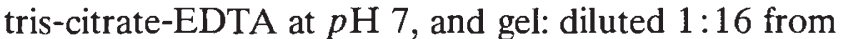
the tray buffer (Ayala et al., 1974). Standard histochemical stainings were used for glucosephosphate isomerase (GPI), malic enzyme (ME) and peptidase (PEP, using glycyl-leucine as substrate) from buffer $\mathrm{i}$, and phosphoglucomutase (PGM), esterase (EST) and phosphoglycerate kinase (PGK) from buffer ii. EST and PGK were stained using fluorescent stains. Other enzymes examined were either monomorphic or did not give scorable results. The abbreviations for the

Table 1 Distribution of brood sizes used in the electrophoretic analyses. The number of mates is the mean of the minimum numbers required to explain the offspring genotypes

\begin{tabular}{lll}
\hline Number of offspring & Number of broods & Minimum number of mates \\
\hline $0-10$ & 26 & 1.54 \\
$10-19$ & 24 & 1.96 \\
$20-29$ & 40 & 1.83 \\
$30-39$ & 9 & 3.11 \\
$40-49$ & 5 & 2.60 \\
$50-59$ & 5 & 2.20 \\
$60+$ & 4 & 1.75 \\
\hline
\end{tabular}


enzymes are given in capital letters and those for the respective loci and alleles in italics.

\section{Statistical methods}

The level of polyandry and the paternal genotypes can be directly inferred from the observed genotypes of the mother and her offspring. The inference is made simple by haploidy of the ant males. The problem is that multiple mating cannot be detected when the mates have identical genotypes, and there is uncertainty about the mate genotype when a heterozygous female has a diploid offspring with an identical heterozygous genotype.

If the proportion of the offspring fathered by the $i^{\text {th }}$ mate is $p_{\mathrm{i}}$, the relatedness $g$ within a brood is

$g=0.25+\frac{1}{2} \Sigma p_{i}^{2}=0.25+1 /\left(2 m_{\mathrm{e}}\right)$,

where $m_{\mathrm{e}}$ is the effective number of mates (Starr, 1984). When the mate contributions $\Sigma p_{i}^{2}$ are estimated from a finite sample of $N$ offspring, the estimate includes also a sampling error. If the observed contributions by the mates are $y_{\mathrm{i}}$, the estimate corrected for the sampling error is

$\Sigma p_{i}^{2}=\left(N \Sigma y_{i}^{2}-1\right) /(N-1)$.

The relatedness among siblings is also affected by departures from random mating. I have earlier examined the case of regular inbreeding (Pamilo, 1985 ). When the inbreeding coefficient due to intranidal mating is $F$, the relatedness is, at least approximately,

$g=0.25+\frac{1}{2} \Sigma p_{i}^{2}+\frac{2 F}{1+F}\left[0.75-\frac{1}{2} \Sigma p_{i}^{2}\right]$.

Gene frequency differences between the sexes lead to an excess of heterozygotes, and the value of $F$ among the offspring is negative. Such a situation is easily transient in the population. However, if the only factor affecting the $F$ value is the gene frequency difference (i.e. the female genotypes have HardyWeinberg frequencies and there is no assortative mating), the expected relatedness among siblings is

$g=0.25+\frac{1}{2} \Sigma p_{i}^{2}+\frac{2 F}{1+F}\left[0.25-\frac{1}{2} \Sigma p_{i}^{2}\right] \frac{1-x_{\mathrm{f}}-x_{\mathrm{m}}}{x_{\mathrm{m}}-x_{\mathrm{f}}}$,

where $x_{\mathrm{f}}$ and $x_{\mathrm{m}}$ are the gene frequencies in females and males. When $x_{\mathrm{f}}=x_{\mathrm{m}}$, the last term is zero $(F=0)$ and the relatedness is as given in eqn (1).

It is also possible to analyse the distribution of the offspring genotypes among the broods and estimate the average relatedness of siblings (Pamilo, 1984). The relatedness is a function of the number and contributions of different mates, and it avoids the problem caused by indistuinguishable mates with identical genotypes. The problem with this approach is that it gives an average relatedness that neglects the variation among the broods. Furthermore, it is not possible with this approach to estimate separately the number of mates and the proportional contributions by them, the estimate depends on the effective number of mates. Departures from random mating also affects the estimate. However, it is useful to compare these estimates with those obtained from the above equations. The relatedness within a brood $\mathrm{j}$ can be written from eqn (1) as

$g_{\mathrm{j}}=0.25+\frac{1}{2}\left(m_{\mathrm{j}} V_{\mathrm{j}}+1 / \mathrm{m}_{\mathrm{j}}\right)$,

where $m_{\mathrm{j}}$ is the number of mates and $V_{\mathrm{j}}$ the variance of their relative contributions. The mean relatedness over all broods is then

$g=0.25+\frac{1}{2} \overline{m V}+1 /(2 H)$,

where $H$ is the harmonic mean number of mates per female. Combining eqn (1) and (6) gives the effective number of mates as

$m_{\mathrm{e}}=H /(1+\overline{H m V})$.

Equations (6) and (7) correct a small error in the earlier derivations of Strassmann et al. (1991) which had a product of means $(\bar{m} \bar{V})$ instead of the mean of the products $(\overline{m V})$.

The average relatednesses among siblings and nest mates is estimated from the observed genotype frequencies using the method of Pamilo (1984) as modified by Queller \& Goodnight (1989) and Pamilo (1990).

\section{Results}

\section{Mendelian segregation}

Three allozyme variants were found segregating in PGM and two variants in the other five enzymes. The most common allozyme of each enzyme is called ' $100^{\prime}$ and the others are named according to the relative mobility of the allozymes. Based on the banding pattern, PGK and PGM are monomeric enzymes, GPI, PEP and EST are dimers and ME is a tetramer.

The interpretation that the observed allozyme variation is genetically determined is supported by a comparison of the maternal and offspring phenotypes (Table 2a). All the offspring are legal, i.e. they carry at least one maternal allele, when the enzyme phenotypes are interpreted to represent genotypes of codominant 
Table 2 Observed mother genotypes and (a) total numbers of offspring genotypes for each mother genotype, and (b) inferred frequencies of mate genotypes separately for each locus. Mate frequencies are calculated by counting each brood once and assigning each male genotype the frequency of offspring derived from the genotype within the brood

\begin{tabular}{|c|c|c|c|c|c|c|c|c|c|c|c|}
\hline \multirow{3}{*}{$\frac{\text { Locus }}{G p i}$} & \multicolumn{2}{|l|}{ Mother } & \multirow{2}{*}{\multicolumn{2}{|c|}{ (a) Diploid offspring }} & & & & & \multirow{2}{*}{\multicolumn{2}{|c|}{ (b) Mates }} & \\
\hline & \multirow[t]{2}{*}{ Genotype } & \multirow[t]{2}{*}{ Number } & & & & & & & & & \\
\hline & & & $100 / 100$ & $100 / 70$ & & & & & 100 & 70 & \\
\hline & $100 / 100$ & 50 & 1118 & 12 & & & & & 49.6 & 0.4 & \\
\hline & $100 / 70$ & 59 & 670 & 663 & & & & & 58.0 & 0 & \\
\hline$M e$ & & & $100 / 100$ & $100 / 95$ & & & & & 100 & 95 & \\
\hline & $100 / 100$ & 51 & 1074 & 43 & & & & & 48.6 & 2.4 & \\
\hline & $100 / 95$ & 28 & 328 & 279 & & & & & 28.0 & 0 & \\
\hline Pep & & & $100 / 100$ & $100 / 80$ & $80 / 80$ & & & & 100 & 80 & \\
\hline & $100 / 100$ & 79 & 1349 & 375 & - & & & & 62.4 & 16.6 & \\
\hline & $100 / 80$ & 22 & 156 & 254 & 86 & & & & 15.3 & 6.7 & \\
\hline Pgm & & & $120 / 120$ & $120 / 100$ & $120 / 70$ & $100 / 100$ & $100 / 70$ & $70 / 70$ & 120 & 100 & 70 \\
\hline & $120 / 120$ & 13 & 82 & 176 & 74 & - & - & - & 2.7 & 7.6 & 2.6 \\
\hline & $120 / 100$ & 49 & 188 & 317 & 44 & 275 & 25 & - & 17.9 & 25.5 & 5.7 \\
\hline & $120 / 70$ & 15 & 53 & 44 & 84 & - & 69 & 22 & 4.5 & 8.4 & 2.1 \\
\hline & $100 / 100$ & 22 & - & 96 & - & 311 & 90 & - & 4.4 & 13.6 & 4.0 \\
\hline & $100 / 70$ & 10 & - & 37 & 42 & 53 & 33 & 18 & 4.6 & 4.7 & 0.7 \\
\hline Est & & & $120 / 120$ & $120 / 100$ & $100 / 100$ & & & & 120 & 100 & \\
\hline & $120 / 120$ & 23 & 52 & 492 & - & & & & 2.8 & 20.2 & \\
\hline & $120 / 100$ & 57 & 80 & 622 & 532 & & & & 7.9 & 49.1 & \\
\hline & $100 / 100$ & 27 & - & 157 & 330 & & & & 9.4 & 17.6 & \\
\hline$P g k$ & & & $100 / 100$ & $100 / 80$ & & & & & 100 & 80 & \\
\hline & $100 / 100$ & 54 & 1075 & 4 & & & & & 53.7 & 0.3 & \\
\hline & $100 / 80$ & 55 & 706 & 659 & & & & & 55.0 & 0 & \\
\hline
\end{tabular}

alleles. Furthermore. the segregation of offspring genotypes follows relatively well the Mendelian expectation. At a biallelic locus, a heterozygous mother should produce heterozygous and homozygous offspring in a 1:1 ratio. There is a slight excess of homozygotes at $\mathrm{Me}$ $\left(\chi^{2}=4.2,1\right.$ d.f., $\left.P<0.05\right)$, but a very close fit at $G p i$, $P e p$, Est and $P g k$ (the values of $\chi^{2}$ are $0.1,0.2,0.0$ and 1.6 , respectively).

The Pgm genotypes among the offspring of heterozygous mothers systematically depart from the 1:1 ratio. Focusing on two alleles at a time, the ratio of homozygotes to heterozygotes is $463: 317$ for the mother genotype $P g m^{120} / P m^{100} \quad\left(\chi^{2}=27.3\right.$, $P<0.001), \quad 75: 84$ for $P g m^{120} / \mathrm{Pgm}^{70} \quad\left(\chi^{2}=0.5\right.$, $0.001<P<0.01)$ and $71: 33$ for $P_{g m}^{100} / P m^{70}$ $\left(\chi^{2}=13.9, P<0.001\right)$. We can also examine the segregation of the alleles of a heterozygous mother when the male has carried the third allelic type, e.g. when the mother is $P g m^{120} / P m^{100}$ and the male has the allele $P g m^{70}$. This comparison shows that the allele $P g m^{120}$ is transmitted slightly more frequently than $P_{g m}{ }^{100}$ $\left(44: 25, \chi^{2}=5.2,0.01<P<0.05\right), P g m^{70}$ more frequently than $\operatorname{Pgm}^{120}\left(69: 44, \chi^{2}=5.5,0.01<P<0.05\right)$, but there is no difference between $\mathrm{Pgm}^{100}$ and $\mathrm{Pgm}^{70}$ $\left(37: 42, \chi^{2}=0.3, \mathrm{~ns}\right)$.
I also tested for the heterogeneity among families for the segregation of the Pgm genotypes (the same six cases described in the previous paragraph). There appears to be a slight heterogeneity in the segregation of the alleles $\mathrm{Pgm}^{120}$ and $\mathrm{Pgm}^{70}\left(\chi^{2}=23.6,9\right.$ d.f., $0.001<P<0.01)$ but not in the other cases. The value of $\chi^{2}$ is 10.4 (10 d.f.) for the segregation of the alleles $\mathrm{Pgm}^{120}$ and $\mathrm{Pgm}^{100}$ of the heterozygous mothers and 2.9 ( 4 d.f.) for the alleles $\mathrm{Pgm}^{100}$ and $\mathrm{Pgm}^{70}$. The values of $\chi^{2}$ when testing the heterogeneity of heterozygous and homozygous offspring among the progenies of heterozygous mothers are 59.9 (46 d.f) for the mother genotype $\mathrm{Pgm}^{120} / \mathrm{Pgm}^{100}, 16.2$ (9 d.f.) for $P_{g m^{120}}$ $\mathrm{Pgm}^{70}$ and 8.2 (8 d.f.) for $\mathrm{Pgm}^{100} / \mathrm{Pgm}^{70}$.

Although the observed segregation of the alleles at Pgm do not strictly obey the expected Mendelian ratios, the departures are not dramatic enough to reject the hypothesis of genetic determination of the allozyme variation. In support of the hypothesis we can note that not a single offspring represents an illegal genotype, and 130 of 131 males electrophoresed in 1990 showed a haploid pattern. Only one male had a heterozygous genotype at $\mathrm{Pgm}$, indicating that this male was diploid.

The offspring genotypes also suggest that the six loci segregate independently of each other. This is tested by 
examining the segregation of alleles when the mother is heterozygous for two loci at the same time (Table 3). Only one of 15 tests shows a significant association (between Gpi and Pgk, $P<0.05$ ).

\section{Number of matings}

Because the ant males are haploid, it is possible to use the mother-offspring genotypic data to infer the genotypes of the mates. The only case where the male genotype cannot be inferred with certainty arises when the mother and her daughter have an identical heterozygous genotype. In that situation we cannot say which of the two alleles comes from the mother and which from the father.

Using the genetic data, the genotypes of the mates are inferred separately for each offspring (Table 4). Less than half of the broods (49, or 44 per cent) can be explained with a single mate type and the highest number of detectable mate types per female is six. Two progenies were fathered by six and one by five male genotypes. The arithmetic mean number of detectable mate types is 1.94 . Ignoring the progenies with less than 10 individuals, the mean is 2.06 . As there is a

Table 3 Independent segregation of the six loci calculated from offspring of mothers heterozygous for the two loci in question. Above the diagonal are chi-squared values and below diagonal are degrees of freedom

\begin{tabular}{lrllrrr}
\hline & $G p i$ & $M e$ & $P e p$ & $P g m$ & Est & \multicolumn{1}{c}{$P g k$} \\
\hline Gpi & - & 5.3 & 7.5 & 11.7 & 9.7 & 36.8 \\
$M e$ & 7 & - & 0.3 & 1.2 & 0.8 & 9.8 \\
$P e p$ & 8 & 1 & - & 3.0 & 3.2 & 10.8 \\
Pgm & 12 & 4 & 5 & - & 17.8 & 22.3 \\
Est & 10 & 3 & 6 & 11 & - & 7.7 \\
Pgk & 24 & 9 & 8 & 16 & 8 & - \\
\hline
\end{tabular}

probability of about 15-17 per cent (depending whether one uses the male allele frequencies deduced from the laboratory cultures or those observed in 1990) that two randomly chosen males have shared the same multilocus genotype, this method does not estimate the true number of mates, only the number of mate types. The detected number of double matings is 38 (Table 4), so the probable number of broods with two identical fathers is about seven. Other corrections for undetected mates are difficult because of the small proportion of highly polyandrous queens and because the detected number of matings also depends on the number of offspring analysed (Table 1).

The observed mating types are presented separately for each locus in Table $2 \mathrm{~b}$. Note that these numbers do not represent the real mating frequencies because not all matings can be separated from each other. However, it is clear that there are some big allele frequency differences between the sexes. Most notably, the loci Gpi, Me and Pgk are almost monomorphic in the males, although all of them are clearly polymorphic in the queens. This means that these loci give practically no information concerning the mating frequency of queens.

From the mating types inferred from the offspring genotypes it is also possible to estimate the relative contributions of each mate and the variance of the contributions using eqn (2). It turns out that one male has normally fathered well over 50 per cent of the offspring. It seems fair to conclude that the males contribute unequally, although their precise contributions can be masked by several mates having an identical genotype. The variances (or $\Sigma p_{i}^{2}$, Table 4) indicate that in progenies with two fathers, one of them produces about 77 per cent of the offspring.

When the estimates of $\Sigma p_{i}^{2}$ are used to calculate relatedness among the offspring using eqn (1), the estimates of relatedness thus obtained are 0.57 for progen-

Table 4 Contributions of different mates as detected from offspring genotypes. Corrected values for the number of broods takes into account undetected double matings by two males of the same genotype. Corrected estimates of $\Sigma p_{i}^{2}$ are based on the eqn 2 and the relatedness estimates $g$ are from eqn 1

\begin{tabular}{|c|c|c|c|c|c|}
\hline \multirow{2}{*}{$\begin{array}{l}\text { Number of } \\
\text { mates }\end{array}$} & \multicolumn{2}{|c|}{ Number of broods } & \multicolumn{2}{|l|}{$\Sigma p_{i}^{2}$} & \multirow[b]{2}{*}{$g$} \\
\hline & Observed & Corrected & Observed & Corrected & \\
\hline 1 & 49 & 42 & 1 & 1 & 0.75 \\
\hline 2 & 38 & 45 & 0.696 & 0.643 & 0.57 \\
\hline 3 & 15 & 15 & 0.501 & 0.443 & 0.47 \\
\hline$>3$ & 11 & 11 & 0.443 & 0.413 & 0.46 \\
\hline Total & 113 & & & & 0.61 \\
\hline
\end{tabular}


ies with two identifiable mates, 0.47 for three mates and 0.46 for more than three mates (Table 4). These values are clearly higher than those expected if the mates had contributed equally (the expected values are $0.50,0.42$ and $0.25-0.38$, respectively). The estimates of $\Sigma p_{i}^{2}$ (Table 4) suggest that the effective number of matings is 1.56 for two actual mates, 2.26 for three mates and 2.42 for more than three mates. Averaging over all broods, eqn (7) gives an average estimate of $m_{\mathrm{e}}=1.48$. The mean relatedness over all progenies, taking into account the correction for undetected double matings (Table 4), is 0.61 .

The level of polyandry can also be estimated directly from the genetic heterogeneity of the offspring. That heterogeneity depends both on the number of mates and on the relative contributions of each of the mates and it can be measured as the genetic relatedness of the offspring within single broods. The estimates for single loci vary greatly, from 0.29 for $G p i$ to 0.70 for Pep (Table 5). As noted above, almost all the mates had been of the same type at $G p i, M e$ and $P g k$. The relatedness estimates based on these loci therefore only reflect the proportions of the queen genotypes and should not be used for estimating polyandry. The other three loci are informative and the mean relatedness from them is 0.60 . Using eqn (1), the relatedness estimate $g=0.60$ corresponds with the effective number of mates being 1.43 , on average.

\section{Population structure}

As noted above, the six loci give conflicting information concerning the genetic heterogeneity within broods. Similarly, the loci give conflicting results concerning the inbreeding coefficient (Table 5). Low estimates of relatedness are connected with an excess of heterozygous individuals.

The allele frequencies in queens are estimated by direct counting of the queen genotypes. The frequencies in the males are estimated in two ways. First, the frequencies can be estimated from the inferred mating types of Table $2 \mathrm{~b}$. Second, I examined new males produced in the population in 1990; they were obtained from only three nests. The allele frequencies in these two cohorts of males are very similar to each other and clearly different from those in the queens (Table 5).

The loci Gpi, $\mathrm{Me}$ and $P g k$ are practically monomorphic in the males, yet each of them has a high frequency of heterozygous queens. The allele frequencies of Est also differ in the two sexes, but the genotype frequencies in the queens agree well with the Hardy-Weinberg expectation. As a result of the gene frequency difference, the Est locus gives a negative estimate of inbreeding, $F$, and the relatedness estimate
Table 5 Estimates of genetic relatedness ( $g$ with 95 per cent confidence limits) and inbreeding $(F)$ calculated from the offspring genotypes, and the frequencies of the rare alleles among the queens, their mates and males samples in 1990

\begin{tabular}{llrllll}
\hline & & & \multicolumn{2}{l}{ Allele frequencies } \\
\cline { 4 - 7 } & & & \multicolumn{4}{c}{ Males } \\
\cline { 4 - 7 } Locus & $g(95 \%$ C.L. $)$ & \multicolumn{1}{l}{$F$} & Queens & Mates & 1990 \\
\hline Gpi & $0.30(0.24-0.36)$ & -0.15 & 0.27 & 0.004 & 0 \\
$M e$ & $0.37(0.24-0.50)$ & -0.07 & 0.18 & 0.03 & 0 \\
$P e p$ & $0.71(0.64-0.78)$ & 0.01 & 0.11 & 0.23 & 0.16 \\
$P g m$ & $0.61(0.55-0.67)$ & 0.10 & & & \\
$P g m^{120}$ & & & 0.41 & 0.31 & 0.32 \\
$P g m^{70}$ & & & 0.12 & 0.14 & 0.23 \\
Est & $0.48(0.38-0.58)$ & -0.19 & 0.48 & 0.19 & 0.29 \\
$P g k$ & $0.29(0.24-0.34)$ & -0.15 & 0.25 & 0.003 & 0 \\
\hline
\end{tabular}

is also lower than that obtained from Pep and $P g m$ (Table 5). If we use eqn (4) to estimate $\Sigma p_{i}^{2}$ by inserting the values of $F, g$ and the gene frequencies $x_{\mathrm{f}}$ and $x_{\mathrm{m}}$ of the Est locus (Table 5), we obtain $\Sigma p_{i}^{2} \approx 0.5$. The reason for this is that the value of $g=0.5$ requires that $\Sigma p_{i}^{2}=0.5$ and the correction term of eqn (4) becomes zero independently of the allele frequencies. We should note, however, that eqn (4) may not be applicable in this situation, because the inferred mating types (Table 2 ) indicate assortative mating. The frequency of $E s t^{120}$ male is 12 per cent among the mates of Est $t^{120} / E s t^{120}$ queens but 35 per cent among the mates of Est $t^{100} /$ Est $^{100}$ queens.

The inbreeding coefficient and the genetic relatedness of worker nest mates are also estimated from the data collected from 14 nests of the $F$. aquilonia population. The estimate of relatedness is 0.056 (s.e. $=0.023$ ).

\section{Discussion}

Although repeated matings by females have been observed in many ants (Page, 1986), genetic studies have often indicated monandry or a low level of polyandry (Page, 1986; van der Have et al., 1988, Ross et al., 1988. Similar mother-offspring analyses as performed here proved Formica pressilabris and $F$. transkaucasica practically monandrous (Pamilo, 1982). The present results clearly demonstrate multiple insemination in $F$. aquilonia. A similar level of polyandry has been detected in two other Formica species, $F$. sanguinea (Pamilo, 1982) and $F$. truncorum (Sundström, 1989). In all three species, the genetic relatedness among siblings falls within the range 0.56-0.63. 
Genetic studies of natural colonies of $F$. truncorum suggest that the level of polyandry is similar for queens in monogynous and polygynous colonies (Sundström, 1989). The estimates for $F$. sanguinea and $F$. aquilonia come from polygynous colonies, the level of polygyny in the latter being exceptionally high for any ant. Polyandry does not contribute significantly in the genetic diversity of the worker force in these ants. The advantage, if any, of polyandry should therefore be at the individual rather then at the colonial level.

High levels of polyandry have been detected in some social wasps and bees that have monogynous colonies. Ross (1986) monitored progenies of two species of Vespula wasps ( $V$. squamosa and Paravespula maculifrons). The females had mated with two to seven males, the relatedness among worker siblings being 0.40 and 0.32 . Honeybee females are also known to mate with many males (Page, 1986). However, the ants with monogynous colonies seem to show a tendency towards monandry or a low level of polyandry, including Aphaenogaster rudis (Crozier, 1973), Solenopsis invicta (Hung \& Vinson, 1976; Ross \& Fletcher, 1985b), S. geminata and S. richteri (Ross et al., 1988), Rhytidoponera confusa and $R$. chalybaea (Ward, 1983), Lasius niger (van der Have et al., 1988), Formica exsecta (Pamilo, 1991b), Myrmica punctiventris (Snyder \& Herbers, 1990), M. lobicornis and $M$. ruginodis (P. Seppä, unpublished data). This agrees with the prediction of the load hypothesis.

While one diploid male of $F$. aquilonia was found in the present study, others have been detected earlier with a low frequency in $F$. pressilabris (Pamilo \& Rosengren, 1984). These observations show that at least some diploid males grow to adults and, hence, can waste the resources of the colony. Both species have highly polygynous colonies and the production of some diploid males may therefore not cause a great burden to the colonies. In the fire ant $S$. invicta monogynous colonies producing diploid males suffer severely and become eliminated at early stages of colony growth, whereas diploid males can arise in polygynous colonies without causing much harm (Ross \& Fletcher, 1986).

In addition to the original question concerning polyandry, a new problem concerning the allele frequency differences between the sexes arose during the study. Such differences could arise in small ant populations where the nests specialize in producing either females or males (Pamilo \& Rosengren, 1983; Nonacs, 1986). If the queens live long, as seems to be the case in the Formica ants (Pamilo, 1991b), the mating types reflect the past population history. However, the new males studied in $F$. aquilonia lacked the same alleles as did the males inferred from the offspring genotypes. This points to a systematic bias in the male genotypes.
There are two explanations for the extremely low variation at $G p i, M e$ and $P g k$ in males. First, it may be that only one type of haploid eggs is formed. That would be the case if the rare allele is linked to a dominant factor which causes the queen always to fertiize the eggs: males would be produced only by females homozygous for the common allele. Second, haploid eggs carrying the rare allele could be produced but eliminated during larval development. This would be the case if the electrophoretic marker is linked with a recessive lethal allele at another locus in the same chromosome.

There are no data to distinguish between these hypotheses. The first of them can be doubted because it is very speculative although sex ratio specialization by queens, observed in many ants (Pamilo \& Rosengren, 1983; Nonacs, 1986), fits this hypothesis. Genetic variation for sex ratio has not been demonstrated in any ants, and the present hypothesis would require specific genes in three chromosomes. Extrachromosomal sex ratio distorters have been observed in Hymenoptera (Werren et al., 1987) as well as in several other organisms (Hurst, 1991) but it is difficult to believe in a linkage of such a factor with three different chromosomal markers in Formica aquilonia.

The second hypothesis can be considered to be more likely because harmful mutations are known to occur and accumulate in the genomes (Pamilo et al., 1987). However, if the alleles are lethal and expressed in the haploid males, we would also expect the frequency to be low in females. The observed high frequencies of the alleles in females cast some doubt over this hypothesis unless there is strong overdominance in the females.

It would be possible to test these two hypotheses by letting single queens produce sexual offspring in laboratory colonies. The hypotheses make clearly different predictions concerning the offspring of heterozygous queens. It should be noted that both of the hypotheses assume linkage disequilibrium between the electrophoretic marker loci and other genes. Such a disequilibrium is population-specific and need not be observed elsewhere; in fact, workers homozygous for the rare alleles have been found regularly in other populations.

Two of the other loci, Pgm and Est, also show features indicating possible selection at them or linked loci. Transmission of the alleles at Pgm depart from normal Mendelian expectation and the mating types inferred from the Est genotypes indicate assortative mating. A recent study of the fire ant $S$. invicta showed allele and genotype frequency differences between both castes and sexes as one homozygous Pgm genotype is consistently eliminated from the queens of poly- 
gynous, but not of monogynous, colonies, apparently because of reproductive competition among the coexisting queens (Ross, 1992). There is no direct evidence suggesting that the observed allele frequency differences in F. aquilonia would be similarly mediated by social behaviour.

\section{Acknowledgements}

I thank J. Kaukinen, M. Ruosteenoja, P. Seppä, P. Tuominen, J. Vainio and K. Vainio for their help during the work and W. Fortelius, R. Rosengren, K. Ross, P. Seppä and L. Sundström for valuable discussions and comments. The study was carried out in the Department of Genetics in Helsinki University and was supported by the Natural Sciences Research Council of Finland.

\section{References}

AYALA, F. J., VALENTINE, J. W., BARR, L. G. AND ZUMWALT, G. S. 1974. Genetic variability in a temperate intertidal phoronid Phoronopsis viridis. Biochem. Genet., 11, 413-427.

CROZIER, R. H. 1973. Apparent differential selection at an isozyme locus between queens and workers of the ant Aphaenogaster rudis. Genetics, 73, 313-318.

CRozier, R. H. 1975. Animal Cytogenetics 3 Insecta 7 Hymenoptera. Gebrüder Borntraeger, Berlin \& Stuttgart.

CROZIER, R. H. AND PAGE, R. E. Jr. 1985. On being the right size: male contributions and multiple mating in social Hymenoptera. Behav. Ecol. Sociobiol., 18, 105-115.

GWYNNE, D. T. 1989. Does copulation increase the risk of predation? Trends Ecol. Evol., 4, 54-56.

HAMILTON, W. D. 1987. Kinship, recognition, disease, and intelligence: constraints of social evolution. In: Itô, Y., Brown, J. L. and Kikkawa J. (eds) Animal Societies: Theories and Facts. Japan Science Society Press, Tokyo, pp. 81-102.

HUNG, A. C. F. AND VINSON, S. B. 1976. Biochemical evidence for queen monogamy and sterile male diploidy in the fire ant Solenopsis invicta. Isozyme Bull., 9, 55.

HURST, L. D. 1991. The incidences and evolution of cytoplasmic male killers. Proc. R. Soc. Lond. B., 24, 91-99.

MACKENSEN, O. 1951. Viability and sex determination in the honey bee. Genetics, 36, 500-509.

MORITZ, R. F. A. 1985. The effects of multiple mating on the worker-queen conflict in Apis mellifera L. Behav. Ecol. Sociobiol., 16, 375-377.

NONACs, P. 1986. Ant reproductive strategies and sex allocation theory. Q. Rev. Biol., 61, 1-21.

PAGE, R. E. Jr. 1980. The evolution of multiple mating behavior by honey bee queens (Apis mellifera L.). Genetics, 96, 263-273.

PAGE, R. E. Jr. 1986. Sperm utilization in social insects. Ann. Rev. Entomol., 31, 297-320.

PAMILO, P. 1982. Multiple mating in Formica ants. Hereditas, 97, 37-45.
PAMILO, P. 1984. Genotypic correlation and regression in social groups: multiple alleles, multiple loci and subdivided populations. Genetics, 107, 307-320.

PAMILO, P. 1985. Effect of inbreeding on genetic relatedness. Hereditas, 103, 195-200.

PAMILO, P. 1990. Comparison of relatedness estimators. Evolution, 44, 1378-1382.

PAMILO, P. 1991a. Evolution of colony characteristics in social insects. II. Number of reproductive individuals. $\mathrm{Am}$. Nature, 138, 412-433.

PAMILo, P. 1991b. Life span of queens in the ant Formica exsecta. Insectes Sociaux, 38, 111-119.

PAMILO, P. AND RoSENGREN, R. 1983. Sex ratio strategies in Formica ants. Oikos, 40, 24-35.

PAMILO, P. AND ROSENGREN, R. 1984. Evolution of nesting strategies of ants: genetic evidence from different population types of Formica ants. Biol. J. Linn. Soc., 21, 331-348.

PAMILO, P., NEI, M. AND LI, W-H. 1987. Accumulation of mutations in sexual and asexual populations. Genet. Res., 49, 135-146.

QUELLER, D. C. AND GOODNIGHT, K. F. 1989. Estimating relatedness using genetic markers. Evolution, 43, 258-275.

ROSENGREN, R. AND PAMILO, P. 1983. The evolution of polygyny and polydomy in mound-building Formica ants. Acta Entomol. Fenn., 42, 65-77.

Ross, K. G. 1986. Kin selection and the problem of sperm utilization in social insects. Nature, 323, 798-800.

Ross, K. G. 1992. Strong selection on a gene that influences reproductive competition in a social insect. Nature, 355 , 347-349.

ROSS, K. G. AND FLETCHER, D. J. C. 1985a. Genetic origin of male diploidy in the fire ant, Solenopsis invicta (Hymenoptera: Formicidae), and its evolutionary significance. Evolution, 39, 888-903.

ROSS, K. G. AND FLETCHER, D. J. C. 1985 b. Comparative study of genetic and social structure in two forms of the fire ant, Solenopsis invicta (Hymenoptera: Formicidae). Behav. Ecol. Sociobiol., 17, 349-356.

ROSS, K. G. AND FLETCHER, D. J. C. 1986. Diploid male production - a significant mortality factor in the fire ant Solenopsis invicta (Hymenoptera: Formicidae). Behav. Ecol. Sociobiol., 19, 283-291.

Ross, K. G., VARGo, E. L. AND Fletcher, D, J. C. 1988. Colony genetic structure and queen mating frequency in fire ants of the subgenus Solenopsis (Hymenoptera: Formicidae). Biol. J. Linn. Soc., 34, 105-117.

SHERMAN, P. W., SEELEY, T. D. AND REEVE, H. K. 1988. Parasites, pathogens, and polyandry in social Hymenoptera. Am. Nature, 131, 602-610.

SHYKOFF, J. A. AND SCHMID-HEMPEL, P. 1991a. Genetic relatedness and eusociality: parasite-mediated selection on the genetic composition of groups. Behav. Ecol. Sociobiol., 28, 371-376.

SHYKOFF, J. A. AND SCHMID-HEMPEL, P. 1991b. Parasites and the advantage of genetic variability within social insect colonies. Proc. R. Soc. Lond. B, 243, 55-58.

SNYDER, L. AND HERBERS, J. M. 1990. Seasonal polydomy and allocation ratios in the ant Myrmica punctiventris. Behav. Ecol. Sociobiol., 28, 409-415. 
STARR, C. K. 1984. Sperm competition, kinship, and sociality in the aculeate Hymenoptera. In: Smith, R. L. (ed.), Sperm Competition and the Evolution of Animal Mating Systems. Academic Press, New York, pp. 427-464.

STRASSMANN, J. E., QUELLER, D. C., SOLIS, C. R. AND HUGHES, C. R. 1991. Relatedness and queen number in the neotropical wasp Parachartergus colobopterus. Anim. Behav., 42, 461-470.

SUNDSTRÖM, L. 1989. Genetic relatedness and population structure in Formica truncorum Fabr. (Hymenoptera, Formicidae). Actes Coll. Ins. Soc., 5, 93-100.

VAN DER hAVE, T., BOOMSMA, J. J. AND MENKEN, S. B. J. 1988. SeX investment ratios and relatedness in the monogynous ant Lasius niger (L.). Evolution, 42, 160-170.

VARVIO-AHO, S. AND PAMILO, P. 1980. A new buffer system with wide applications. Isozyme Bull., 13, 114.

WARD, P. S. 1983. Genetic relatedness and colony organization in a species complex of ponerine ants I. Phenotypic and genotypic composition of colonies. Behav. Ecol. Sociobiol., 12, 285-299.

WERREN, J. H., SKINNER, S. W. AND HUGER, A. M. 1987. Male-killing bacteria in a parasitic wasp. Science, 231, 990-992.

wiLliams, G. C. 1975. Sex and Evolution. Princeton University Press, Princeton. 